\title{
2.5 AN OBSERVATIONAL AND HIGH-RESOLUTION MODEL ANALYSIS OF GALE WIND EVENTS IN THE GULF OF CALIFORNIA
}

\author{
Ariel E. Cohen*1 and J. P. Cangialosi \\ ${ }^{1}$ NOAA/National Weather Service Forecast Office, Jackson, Mississippi \\ ${ }^{2}$ NOAA/National Hurricane Center, Miami, Florida
}

\section{Introduction}

Forecasters at the Tropical Analysis and Forecast Branch (TAFB) of the National Oceanic and Atmospheric Administration's (NOAA's) National Hurricane Center in Miami, FL are responsible for providing High Seas Forecasts to the Gulf of California, also known as the Sea of Cortez. High Seas Forecasts provide event-driven forecasts of strong wind (20 kt (10.3 $\left.\mathrm{m} \mathrm{s}^{-1}\right)$ or higher) and high wave $(8 \mathrm{ft}(2.4 \mathrm{~m})$ or higher) areas. The Gulf is an ofttraversed waterway and provides a particularly unique challenge to forecasters due to local wind enhancements driven by the highly-variable terrain that bounds the Gulf.

In autumn 2008, forecasters were surprised a number of times when a ship meandering in the northern Gulf reported northwest to north near-surface winds over gale force while all global model guidance was depicting $10-\mathrm{m}$ winds no higher than $25 \mathrm{kt}\left(12.9 \mathrm{~m} \mathrm{~s}^{-}\right.$ $\left.{ }^{1}\right)$. Forecasters investigated these observations, and found that they originated from the NOAA Research Vessel (R/V) David Starr Jordan, whose primary mission was to study the biological and physical oceanography of the Gulf of California in autumn 2008. During this mission, they also provided meteorological measurements of particular help to forecasters at TAFB. Forecasters immediately questioned the quality of the observations, given their consistent high-bias relative to global Numerical Weather Prediction model output. However, after a number of events and realizing the credibility of the observations from the NOAA R/V's calibrated wind sensor, analysis revealed that particular synoptic patterns over the mid latitudes consistently occurred with these reported gale wind events. Additionally, anecdotal evidence of these wind events are provided in Jack Williams's Baja Boaters' Guide (Williams 1988), which suggests frequent gale force wind events in the Gulf of California during autumn time. Given this additional evidence, TAFB forecasters quickly realized that global models insufficiently resolved these gap wind events, as well as many other gap wind events across the Intermountain West (e.g., Mass and Albright 1985; Sharp and Mass 2002).

${ }^{*}$ Corresponding Author Address: Ariel Cohen, National Weather Service, Jackson, MS Weather Forecast Office, 234 Weather Service Dr., Flowood, MS 39232; e-mail: Ariel.Cohen@noaa.gov.
This led to recent initiatives to investigate the synoptic scale and mesocale environments that support the gale wind events as recorded by the R/V David Starr Jordan, the results of which are presented in the present work. We present forecast tools based on observations and high-resolution modeling.

\section{Methodology}

Given the absence of frequent wind observations and inadequate model forecasts of low level winds in the Gulf, TAFB forecasters have come to rely on a conceptual model developed in this study to provide techniques in synoptic scale pattern recognition that global models can more adequately resolve. Synoptic pattern recognition is invaluable in forecasting these events and can be applied to global models, which are known to insufficiently resolve the low-level momentum fields for these events at the mesoscale level (e.g., Sharp and Mass 2002).

To identify meteorological patterns associated with gale wind events, as well as non-gale wind events, we developed a set of criteria to stratify wind speed data provided on an hourly basis by the R/V David Starr Jordan after the conclusion of its mission. We chose to call a "gale event" a day during which at least three consecutive hours were logged with gale force winds (i.e., sustained winds of 34 to $47 \mathrm{kt}$ ( 17.5 to $\left.24.2 \mathrm{~m} \mathrm{~s}^{-1}\right)$ ), and we chose to call a "marginal wind event" a day during which at least three hours (not necessarily consecutive) were logged with winds of 15 to $25 \mathrm{kt}$ ( 7.7 to $\left.12.9 \mathrm{~m} \mathrm{~s}^{-1}\right)$, but no gale force winds were reported. We excluded shorter-duration gales, because forecast periods in the High Seas Forecast product span at least 3 hours in most cases. There are certainly many other stratification schemes we could have performed. However, our goal is to distinguish the more high impact gale events from the minimal threshold for inclusion in the High Seas Forecast product (i.e., winds of $20 \mathrm{kt}$ $\left(10.3 \mathrm{~m} \mathrm{~s}^{-1}\right)$ ) (National Weather Service Instruction 10311).

Based on our criteria and excluding one atypical case, we analyzed a total of 6 "gale events" (G) and 7 "marginal wind events" (MW). We used the National Centers for Environmental Prediction (NCEP) Global Reanalysis (Kalnay et al. 1996) composite data provided by the NOAA Earth System Research Laboratory (ESRL) Physical Sciences Division (PSD) to create mean and anomaly plots of several meteorological variables for gale and non-gale 
events. The most distinguishing features between the G's and MW's were found in the 500-hPa height, mean sea level pressure (MSLP), lifted index (LI), and 850-hPa temperature fields $(500-\mathrm{hPa}$ height and MSLP fields shown in Figures 1 and 2). Composite mean fields are computed by calculating the mean of each variable among all recorded $\mathrm{G}$ or MW dates. Anomaly fields are computed by calculating the departure of each variable from its climatological average between 1968 and 1996 on a case-by-case basis followed by averaging the anomalies.

\section{Conceptual Model}

Figure 1 provides mean and anomaly $500-\mathrm{hPa}$ heights for $G$ and MW cases. For the G's, anomalously strong $500-\mathrm{hPa}$ ridging appears to be associated with a highly-amplified, long-wave 500$\mathrm{hPa}$ ridge over the eastern Pacific and west coast of the United States, with a medium-wavelength 500$\mathrm{hPa}$ trough over the central U.S.
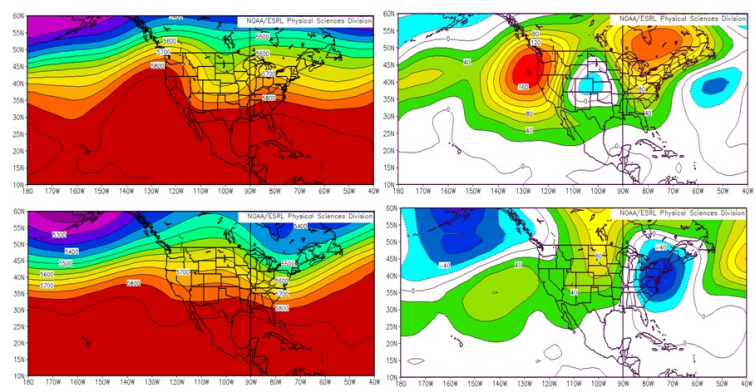

Figure 1: Composite mean (left column) and anomaly (right column) 500-hPa heights (geopotential meters) for G (top row) and MW cases (bottom row).

We infer that strong negative differential vorticity advection downstream of the $500-\mathrm{hPa}$ ridge axis supports deep-layer subsidence over the Rocky Mountains which results in the development of anomalously strong surface high pressure as seen in the mean sea level pressure (MSLP) fields for $G$ cases in Figure 2. These $500-\mathrm{hPa}$ and surface patterns are also associated with the positive phase of the Pacific North American pattern, which is also known to support gale wind events in the Gulf of Tehuantepec (Cobb et al. 2002). For the MW cases, 500-hPa waves show less amplitude, with no particularly strong anomalies in either the MSLP or 500-hPa fields.

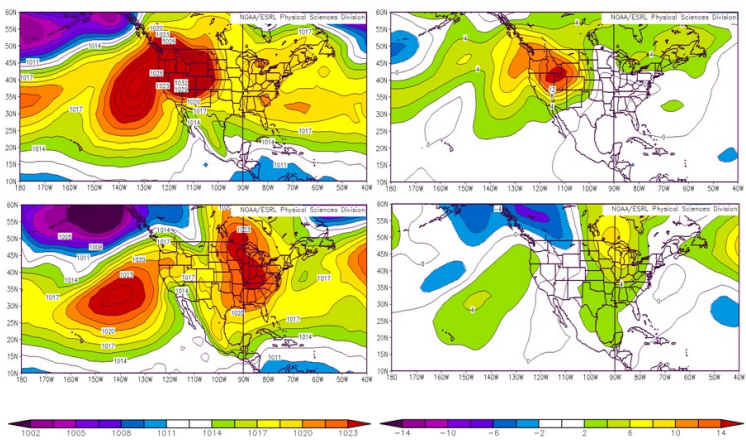

Figure 2: Composite mean (left column) and anomaly (right column) mean sea level pressure $(\mathrm{hPa})$ for $\mathrm{G}$ (top row) and MW (bottom row) cases.

The strong surface high depicted for G's in Figure 2, centered over the northern Rockies, is found to be north of a $850-\mathrm{hPa}$ front. The $850-\mathrm{hPa}$ level was chosen to diagnose near surface frontal passage, as it provides an approximate pressure for the surface in the west central and southwest continental United States (CONUS). The $850-\mathrm{hPa}$ front is found to surge south or southwestward into the northern Gulf of California at the leading edge of the airmass anchored by the strong surface high over the northern Rockies. When the post-frontal cooler airmass overlays relatively warmer Gulf waters, we speculate that increased low-level lapse rates above the water surface enhances turbulent mixing and surface wind speeds.

It is the combination of the aforementioned synoptic features and the unique topography over the western U.S. and Mexico that favors gale wind events in the Gulf of California. Figure 3 presents the geographical layout that supports the G's.

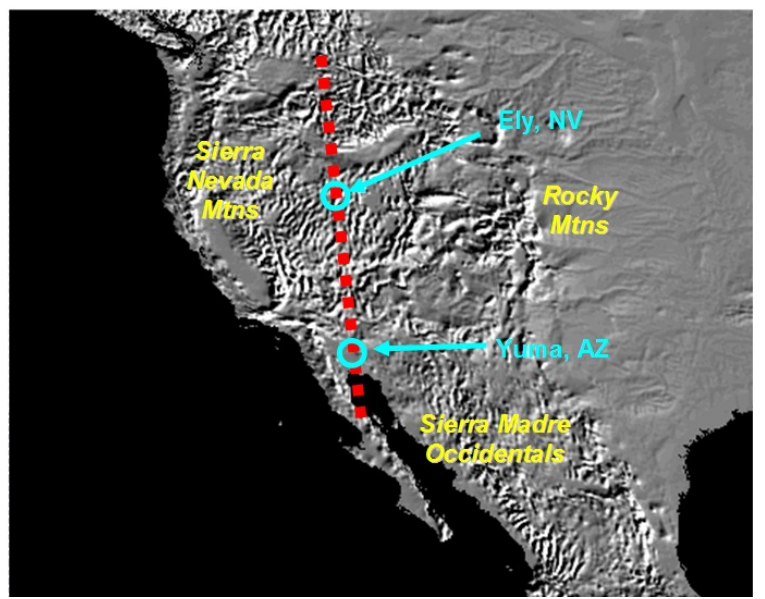

Figure 3: Relief map illustrating the geographical layout that supports the G's. Elevated surfaces indicate higher terrain. (Courtesy of NOAA's National Geophysical Data Center)

The Gulf of California lies in the north-northwest-tosouth-southeast valley bounded by the Sierra Madre Occidentals to the east, the higher terrain of the 
Intermountain West to the north, and the Baja California Mountains to the west. The meridional component of motion is driven by the strong north-tosouth pressure gradient force between the strong surface high pressure over the northern Rockies and lower pressure over the Gulf. This flow is then further accelerated by the perturbation pressure gradient force driven by the orientation of the Gulf relative to the aforementioned pressure gradient considering mass conservation principles. Furthermore, downslope flow off higher terrain to the north accelerates the flow. Finally, maximum winds were found between 1000 UTC and 1200 UTC (2:00 a.m. and 4:00 a.m. LST), when katabatic drainage flow off surrounding higher terrain is maximized by the presence of clear skies (as inferred from total precipitable water products and infrared satellite, for example).

\section{Gulf of California Gale Wind Potential Index}

Based on the pattern that links the strong surface pressure gradient over the southwest United States to gale wind events, we attempted to find combinations of western United States MSLP observations that capture this gradient and best discriminates between the G's and the MW's. Of all combinations, the difference in MSLP between Ely, Nevada and Yuma, Arizona best discriminates between the G's and the MW's with a P-value of 0.001 with a $50^{\text {th }}$ percentile of around $12-13 \mathrm{hPa}$. The small sample size required us to use a two-sample T-test that assumes unequal variances to derive a $\mathrm{P}$-value. We agree that this sample is not as statistically robust as we would like, and a larger dataset would likely lend more credence to this study's results. Nevertheless, we feel this index is physically-grounded, and sufficiently discriminates between the G's and the MW's for short-term forecasting. Among our six $G$ cases and seven MW cases, the differences in MSLP between Ely and Yuma (taken as Ely - Yuma) are summarized in the box-and-whiskers plot in Figure 4, which provide $0^{\text {th }}, 25^{\text {th }}, 50^{\text {th }}, 75^{\text {th }}$, and $100^{\text {th }}$ percentiles $\left(0^{\text {th }}\right.$ and $25^{\text {th }}$ percentiles are identical for the MW cases). This figure shows the large spread in this index between the larger part of the $\mathrm{G}$ events and the MW events, and indicates some reliability in the discriminatory power of this index between these two classes of events.

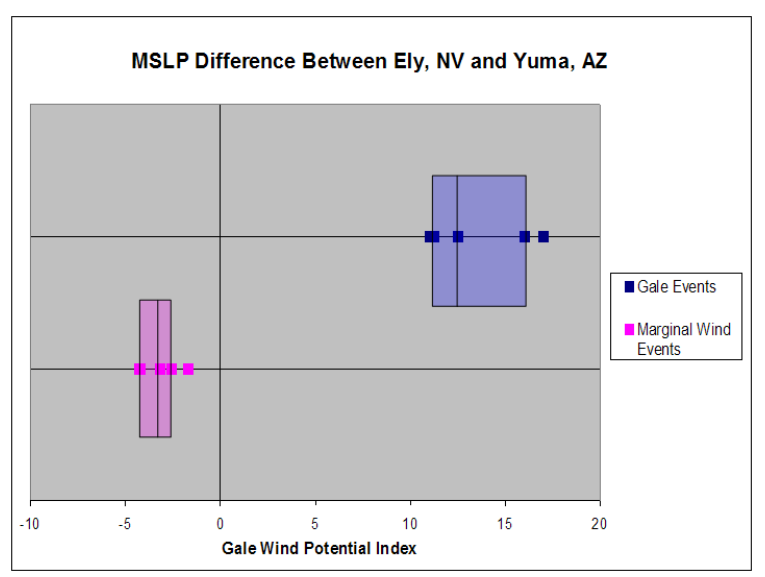

Figure 4: Box-and-whiskers plots for $\mathrm{G}$ and MW cases, presenting $0^{\text {th }}, 25^{\text {th }}, 50^{\text {th }}, 75^{\text {th }}$, and $100^{\text {th }}$ percentiles of each separate dataset.

Such an index needs be considered as guidance in this forecast process and could be used in conjunction with high resolution model forecasts to more accurately forecast these events.

\section{High-Resolution Modeling}

In the preceding sections, we have developed a general conceptual model that forecasters can use to understand synoptic conditions favorable for higher impact gale wind events in the Gulf of California. The development of this conceptual model provides a method for pattern recognition using global models. However, these global models are known to inadequately resolve the magnitude and spatial distribution of these events due to their relatively coarse resolution and resultant inability to resolve fine-scale topographical variations. Despite these limitations, TAFB forecasters have used meteorological model output at multiple levels in the atmosphere (e.g., 30-m level, 60-m level, and 925-mb level) to forecast the potential for higher momentum air aloft to be transported to the surface for gap wind events (e.g., Gulf of Tehuantepec (Cobb et al. 2002)). In this section, we will explore the usefulness of a high resolution model (i.e., the Pennsylvania State University-NCAR Mesoscale Model (MM5)) to simulate gap wind events in the Gulf of California.

We use the high resolution, non-hydrostatic, and $5^{\text {th }}$ generation Pennsylvania State University-NCAR Mesoscale Model (MM5) to simulate winds in the Gulf of California for a few cases revealed by the R/V David Starr Jordan. This version of the MM5 (Grell et al. 1994) has been used to simulate a number of related gap wind events (e.g., Schultz et al. 1997). We chose a model configuration that used two nested domains. The outer domain used a horizontal grid resolution of $15 \mathrm{~km} \times 15 \mathrm{~km}$ (300 grid points $\times 300$ grid points), while the inner domain used a horizontal grid resolution of $5 \mathrm{~km} \times 5 \mathrm{~km}$ (211 grid points $\times 103$ grid points) and encompasses the Gulf of California (Fig. 5). 


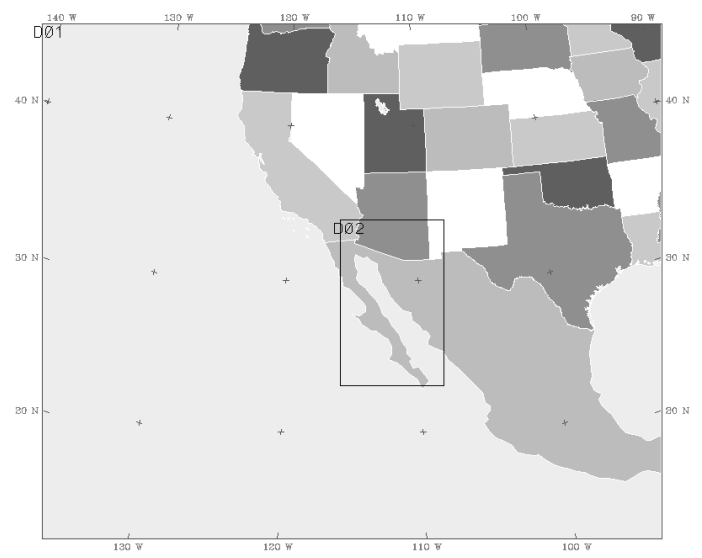

Figure 5: Domain configuration for MM5 runs.

Both domains were forced to interact with each other in a two-way feedback process. Both domains used 30 vertical sigma levels, with 11 sigma levels in the planetary boundary layer. The Global Forecast System (GFS) forecast fields (Kalnay et al. 1990) including Reynolds' weekly sea surface temperatures (SST), provided the initial and lateral boundary conditions for the domains (Reynolds and Smith 1994).

The first simulation we will consider was for an event that occurred on 15-16 November 2008. We present the results of the 96-hour long simulation that was initialized at 00 UTC 14 November 2008, about 36 to 48 hours prior to the peak of the wind event based on ship observations (i.e., the approximate maximum warning lead time that is currently provided by the High Seas Forecast). Figure 6 provides $10-\mathrm{m}$ wind speed output from the MM5 for 12 UTC 15 November 2008, while Figure 7 provides verification from a QuikSCAT pass around 1330 UTC 15 November 2008. Note, the R/V David Starr Jordan recorded winds at $22.9 \mathrm{~m}$ above sea level.

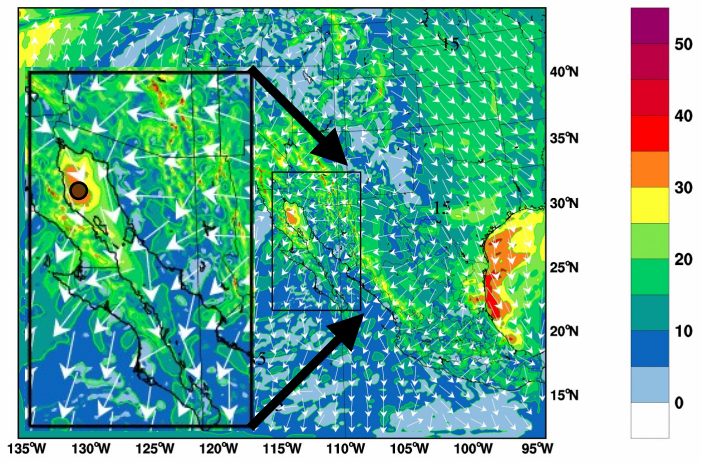

Figure 6: MM5 10-m wind speed output for a simulation initialized 0000 UTC 14 November 2008 valid 1200 UTC 15 November 2008 (a 36-hour forecast), with the dot indicating the approximate position of the R/V David Starr at this time.

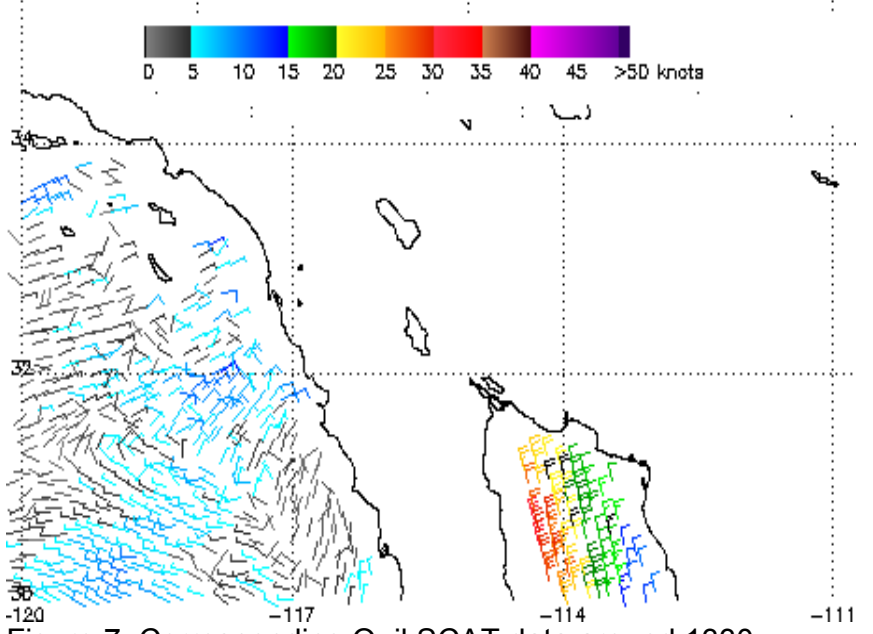

Figure 7: Corresponding QuikSCAT data around 1330 UTC 15 November 2008, which provide swaths ocean wind vectors from the polar-orbiting National Aeronautics and Space Administration (NASA) Quick Scatterometer (QuikSCAT) satellite.

It is immediately apparent that the MM5 provided a remarkably realistic and reliable depiction of the strength and geographical distribution of this wind event. Maximum winds forecast by the MM5 and verified by the QuikSCAT pass were $35 \mathrm{kt}$ $\left(18.0 \mathrm{~m} \mathrm{~s}^{-1}\right)$. The $10-\mathrm{m}$ wind velocity output from the GFS is provided in Figure 8 for comparison, which inadequately forecasts the intensity during this event.

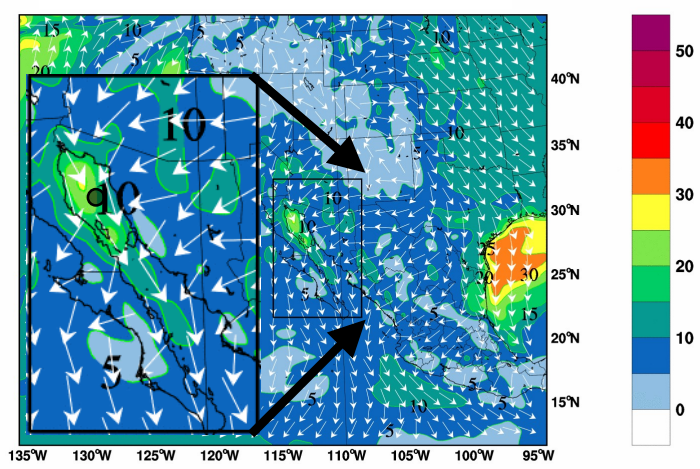

Figure 8: GFS 10-m wind speed output for a simulation initialized 0000 UTC 14 November 2008 valid 1200 UTC 15 November 2008 (a 36-hour forecast).

With wind speed data provided by the R/V David Starr Jordan, we can compare forecast wind speeds derived from the MM5 and GFS with those measured by data collected by the R/V David Starr Jordan. Figure 9 shows a meteogram that compares observed 
wind speeds from the ship and 10-m wind speeds forecast by the MM5 and GFS for the 0000 UTC 14 November 2008 initialization. We extracted the forecast wind speeds based on MM5 and GFS output at the closest gridpoint to the ship as it traversed the Gulf of California. These forecast wind speed are then compared to the wind speeds as measured by the ship, providing us with a ship-following verification dataset.

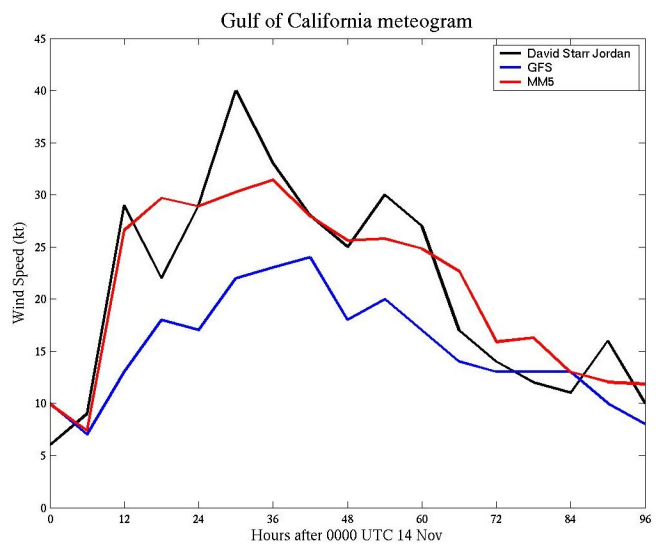

Figure 9: Meteogram comparing 10-m wind speeds derived from the MM5 and GFS for points along the path of the ship, with the corresponding wind speeds measured from the ship.

The agreement between MM5 output and ship observations is remarkably good for the duration of the event. In particular, the MM5 appears to accurately predict the rapidity of the initial wind speed increase. Throughout the simulation, the GFSmodeled wind speeds were too weak. Additionally, both the MM5 and GFS accurately handle the timing of wind speed maxima, though neither the GFS nor the MM5 appear to accurately depict the strength of these peaks. Note, the MM5 forecasted winds did not reach gale force for the ship's locations. However, gales were still reported elsewhere for this event, as seen in Figure 6.

\section{Conclusions}

The National Oceanic and Atmospheric Administration's (NOAA's) National Hurricane Center $(\mathrm{NHC})$ in Miami, FL issues High Seas Forecasts to portions of the eastern Pacific Ocean, including the Gulf of California. These forecasts include 10-meter winds and significant wave heights with a threshold of winds of greater than $20 \mathrm{kt}$ or significant wave heights of at least $8 \mathrm{ft}$. The Gulf of California is a critical area for the recreation and fishing industries. Winds in the Gulf of California are highly modulated by nearby terrain variations. This provides a unique forecast challenge, especially in the absence of regular surface observations. In October and November 2008, the NOAA Research Vessel David Starr Jordan was stationed in the northern Gulf of California and occasionally reported gale force winds, which operational models regularly missed. A ship log of these events provided the basis for determining mean and anomaly fields for a handful of meteorological variables, from which we present a conceptual model for the synoptic scale environment supporting these events. An index based on the MSLP difference between Ely, NV and Yuma, AZ was developed to measure the potential for gales, which is found to be statistically significant in discriminating between gale and non-gale events. Doubly-nested MM5 runs centered on the Gulf of California appear to resolve these gales, lending credence toward the need for high-resolution modeling in areas of highly-variable terrain. Relatively small errors are found in MM5 output using QuikSCAT data as verification.

\section{Acknowledgments}

The authors thank the staff of NHC's TAFB for numerous discussion and motivation to further study gale wind events in the Gulf of California, particularly Mr. Waldemar Barnes and Mr. Eric Christensen. Additionally, this work would not have been made possible without the computing resources provided by Dr. Shuyi Chen and Mr. Derek Ortt of the University of Miami's Rosenstiel School of Marine and Atmospheric Sciences and particularly their support in running the MM5 model. We also thank Dr. Chris Landsea of the NHC and Mr. Erik Pytlak of the National Weather Service Forecast Office in Tuscon, Arizona for thorough reviews of earlier editions of this work. Their comments greatly improved the quality of this work, along the reviews of three anonymous reviewers.

\section{References}

Cobb III, H. D., D. P. Brown, and R. Molleda, 2002: Use of QuikSCAT imagery in the diagnosis and detection of Gulf of Tehuantepec wind events 19992002. Preprints, $12^{\text {th }}$ Conference on Satellite Meteorology and Oceanography, Long Beach, CA, Amer. Meteor. Soc., available online at http://ams.confex.com/ams/pdfpapers/54957.pdf.

Grell, G. A., J. Dudhia, and D.R. Stauffer, 1994: A description of the fifth-generation Penn State/NCAR mesoscale model (MM5). NCAR Tech. Note NCAR/TN-398+STR, 122 pp.

Kalnay, E., M. Kanamitsu, and W. E. Baker, 1990: Global numerical weather prediction at the National Meteorological Center. Bull. Amer. Meteor. Soc., 71, 1410-1428.

----, and Coauthors, 1996: The NCEP/NCAR 40-Year Reanalysis Project. Bull. Amer. Meteor. Soc., 77, 437-471. 
Mass, C. F., and M. D. Albright, 1985: A severe windstorm in the lee of the Cascade Mountains of Washington State. Mon. Wea. Rev., 113, 12611281.

National Weather Service Instruction 10-311.

Operations and Services: Marine and Coastal Weather Services, NWSPD 10-3. Offshore, Navtex, High Seas, and Marine Forecast Services. [Available Online:

http://www.nws.noaa.gov/directives/sym/pd01003011 curr.pdf]

NOAA's National Geophysical Data Center (NGDC). Topographic Data and Images. [Available Online: http://www.ngdc.noaa.gov/mgg/topo/]

Reynolds, R. W., and T. M. Smith, 1994: Improved global sea surface temperature analyses using optimum interpolation. J. Climate, 7, 929-948.

Schultz, D. M., W. E. Bracken, L. F. Bosart, G. J. Hakim, M. A. Bedrick, M. J. Dickinson, and K. R. Tyle, The 1993 superstorm cold surge: frontal structure, gap flow, and tropical impact. Mon. Wea. Rev., 125, 5-39, 1997.

Sharp, J., and C. F. Mass, 2002: Columbia Gorge gap flow - Insights from observational analysis and ultra-high-resolution Simulation. Bull. Amer. Meteor. Soc., 83, 1757-1762.

Williams, J., 1988. Baja Boater's Guide: Volume II -The Sea of Cortez. H.J. Williams Publications. 